С.П. Сєдаш ${ }^{1}$, О.О. Возний ${ }^{2}$

${ }^{1}$ Льотна академія національного авіаційного університету, Кропивницький

${ }^{2}$ Харківський національний університет Повітряних Сил ім. І. Кожедуба, Харків

\title{
МОДЕЛЬ АВТОМАТИЗОВАНОГО УПРАВЛІННЯ ФОРМУВАННЯМ НАВИЧОК У ОПЕРАТОРІВ СКЛАДНИХ СИСТЕМ
}

В статті розроблено модель автоматизованого управління формуванням навичок в операторів складних систем у ході професійної підготовки з застосуванням комп'ютерних тренажерів. Особливість моделі полягає у використані нових параметрів при визначенні керуючих впливів з урахуванням багаторазових повторень вправ, щу забезпечує необхіднии рівень інформаційної підтримки навчаємого, $і$ підвищує ефективність придбання здатності до самоконтролю якості виконання операцій. Наведена структурна схема даної системи, проведено опис ї̈ складових. 3'ясовано, щзо оператор складних систем повинен володіти навичками своєчасного, точного виконання необхідних операчій, спираючись на знання про бажану траєкторію процесу, оцінюючи фактичне протікання прочесу, вибираючи з можливих найбільш ефективні дії. Розробка математичних моделей здійснюється з застосуванням теорії ймовірностей, теорії множин, формалізація процесу діяльності оператора складних систем здійснюється за допомогою теорії графів та мереж Петрі.

Ключові слова: авіаџійні фахівиі, ергатичні системи, мережі Петрі, оператор складної системи, сенсомоторні навички, управління повітряним рухом.

\section{Вступ}

Постановка проблеми. Ефективність функціонування складних технологічних процесів багато в чому визначається ступенем підготовки операторів. Узагальнюючи поняття оператора в галузі цивільної авіації до них можна віднести пілотів, диспетчерів управління повітряним рухом, обслуговуючий персонал аеродромного обладнання. Низька якість роботи, значний рівень аварійності найчастіше є наслідком недостатньої сформованості в операторів професійних сенсомоторних навичок. Оператор повинен володіти навичками своєчасного, точного виконання необхідних технологічних операцій, спираючи на знання про бажану траєкторію процесу, оцінюючи фактичне протікання процесу, вибираючи 3 можливих найбільш ефективні дії. Отже підвищення ефективності професійної підготовки операторів з метою формування в них необхідного рівня сенсомоторних навичок на основі науково обгрунтованих моделей та методів $\epsilon$ актуальним завданням. Для цього застосовуються тренажерні комплекси та автоматизовані системи навчання (ACH), які мають значне розповсюдження в підготовці фахівців цивільної авіації.

Аналіз останніх досліджень і публікацій. Роботи [1-4], є важливим внеском у вивченні проблем ітеративного навчання, зокрема математичного моделювання цього процесу. Ітеративне навчання, як правило, характеризується асимтотичними кривими, що можуть бути апроксимовані експонентними кривими [1]. Феномен ітеративного навчання є одним 3 важливих аспектів для розвитку моделей і методів контролю сенсомоторных навичок операторів складних систем. У [5-6] пропонується ймовірнісна модель, яка описує структурну модель навчання та рекурентний метод іiі обчислення для визначення ступеня виконання завдань на деякій стадії навчання. Даний підхід дозволяе динамічно формувати криву научання в залежності від результатів і швидкості навчання студента. Зокрема, у залежності від успішності, відбувається збільшення або зменшення множини завдань, які необхідно пройти, з визначеної множини. Успіх виконання вправ визначається за такими булевими критеріями, як безпомилковість і своєчасність виконання. У роботі [6] автори розширюють підхід можливістю поступового переходу від завдань одного типу, до завдань іншого. Це досягається поступовим збільшенням імовірності вибору завдань другого типу по мірі проходження завдань першого типу та зменшення ймовірності вибору завдань першого типу. В статті [7] аналізується безперервний процес навчання 3 погляду формування процедурних знань, їх вплив на формування декларативних знань, а також їх взаємний вплив у процесі прийняття рішень. Автори розробили гібридну модель “Clarion”, яка описує ці аспекти і представляється у виді двох відповідних рівнів. Перший рівень представлений у виді чотирьохшарової асоціативної мережі для прогнозування дії на основі поточної ситуації. Другий рівень містить множину правил для прийняття рішень.

У літературі [8-10] аналізується застосовність онтологій в описі предметної області та їх викорис- 
тання для підвищення ефективності навчання. В [9] більш докладно розглядається даний аспект для освоєння компетенцій 3 використанням тренажерних комплексів. У [10] досліджуються комп'ютерні тренажери для навчання операторів складних технологічних процесів, головним чином у хімічній і нафтохімічній галузях. Представлено методику комп'ютерного тренінгу, заснованої на когнітивній моделі формування базових і комплексних операторських навичок. Література [10] присвячена головним чином керуванню процесом формуванням навичок контролю технологічного процесу, що протікає автоматично. В літературному огляді також необхідно виділити роботи [11-15], які присвячені застосуванню адаптивних тренажерних систем та тренажерів для підготовки диспетчерів управління повітряним рухом як операторів складних систем. Таким чином, незважаючи на наявність значної кількості наукових досліджень в області автоматизації професійного навчання можна зробити висновок про недостатнє розкриття моделей та методів автоматизації управління формуванням професійних компетенцій операторів складних систем у частині формування сенсомоторних навичок.

Метою статті $\epsilon$ розроблення моделі автоматизованого управління формуванням навичок у операторів складних систем для підвищення описових можливостей процесу навчання.

\section{Виклад основного матеріалу}

У процесі навчання оператора складної системи на комп'ютерному тренажері, що полягає в проходженні комплексу вправ, кожна з яких призначене для формування сенсомоторного навику виконання технологічної операції, вирішується завдання оптимізації виду:

$$
T_{\text {навч. }}=\sum_{g=1}^{N_{y n p}} T_{g} \rightarrow \min ,
$$

де $\forall_{g}=\overline{1, N_{\text {yпр }}}, T_{g}=f_{\text {вик }}\left(U_{g}^{p i u}, U_{g}^{p e \kappa}\right)=\sum_{v=1}^{N_{g}^{\text {guк }}} T_{g \nu}$

- час $T_{g}$ багатократного виконання $g$-ої вправи залежить від множини прийнятих рішень $U_{g}^{\text {pim }}$ по завершенню кожного $v$-го виконання та множини рекомендуючих дій $U_{g}^{p e \kappa}$ навчаємому в процесі кожного $v$-го виконання ( $T_{g v}-$ час $v$-го виконання $g$ -ої вправи); $\quad \forall_{g}=\overline{1, N_{y n p}}, \quad K_{g h \geq} K_{g h}^{n o p .}$ - якість виконання операції, що моделюється в $g$-ій вправі, визначається параметрами $K_{g h}$ (де $h=\overline{1, N_{\text {nop. }}}$ ), повинно відповідати нормативам, тобто пороговим значенням $K_{g h}^{n o p}$.

$$
\forall_{g}=\overline{1, N_{y n p .}}, \quad N \geq \forall_{g}=\overline{1, N_{y n p}} \text { - вправа, ви- }
$$

конана задану кількість разів підряд на потрібному рівні якості (тобто дія закріплена до автоматизму).

Іншими словами за мінімальний час навчання необхідно, щоб виконання операції було закріплено до автоматизму на заданому рівні якості. Сукупність залежностей між параметрами математичної моделі наведено на рис. 1. На основі теорії множин і математичної логіки далі представимо опис процесу функціонування кожного з блоків (див. рис. 1), що відповідають за різні складові процесу управління і враховуючу специфіку сенсомоторних навичок.

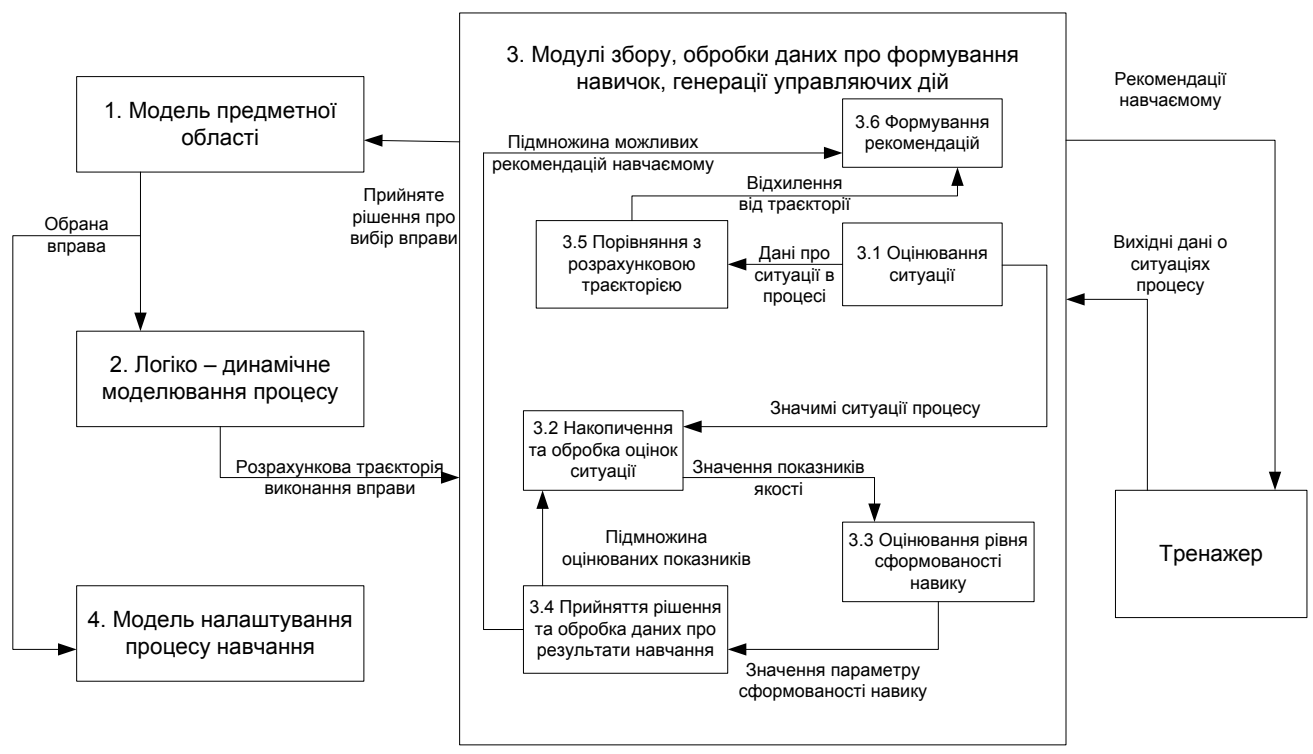

Рис. 1. Підсистема автоматизованого управління формуванням навичок Джерело: розроблено авторами за даними $[2 ; 5]$. 
Взаємний зв'язок операцій, які виконуються оператором в процесі роботи, можна представити орієнтованим графом (моделлю предметної області (блок 1, рис. 1). $G_{y n p}=\left\langle M_{o}, M_{\text {вз. }}\right\rangle$, де $M_{o}-$ множина операцій (вершин графа $v_{g} \in M_{o}$ ), виконання кожної з якої потребує сформованості деякого навику; $M_{\text {вз. }}$ - множина дуг графа, що показує взаємний зв'язок між операціями. Кожна дуга графа

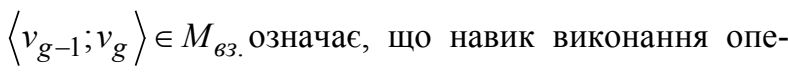
рації $v_{g}$ заснований на навику виконання операції $v_{g-1}$. Приклад такого графа представлено на рис. 2.

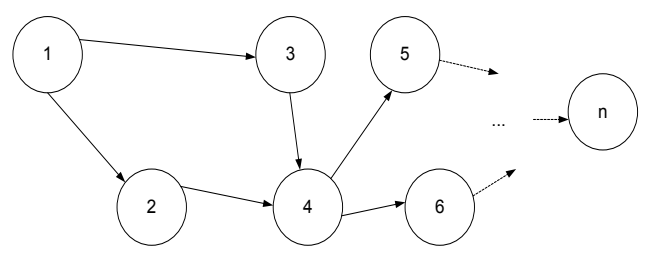

Рис. 2. Приклад графу зв'язків операцій

Джерело: розроблено авторами за даними [7-8].

Оскільки кожній операції відповідає вправа на тренажері, то даний граф визначає послідовність виконання вправ. Конкретний маршрут на графі $G_{y n p}$ використовується при проходженні вправи на тренажері, що визначається стадією та завдання навчання операторів.

Набір виконуємих взаємопов'язаних вправ, які визначаються графом $G_{y n p}$, забезпечує обробку оператором складної системи дій по керуванню процесом, в тому числі і ліквідацію нештатних та аварійних операцій.

В блоці 2 (рис. 1) задається множина логікодинамічних моделей технологічного процесу складної системи, які доцільно представити у вигляді мереж Петрі. Для виконання деякої операції в складній системі $v_{g} \in M_{o}$, використовується множина засобів введення (пульти, кнопки, важелі, джойстики, тощо) $M_{6 .}\left(F_{B .}: M_{o} \rightarrow M_{6 .}\right)$. При виконанні операції здійснюються впливи на ці елементи: $V_{в}=\left\{r_{i}\left(t_{q}\right) \mid q=\overline{1, N_{m}}\right\}$ - можливі положення кнопки, важеля, джойстика, тощо. Отже, для будь-якого $v_{g} \in M_{o}$, взаємозв'язок між множинами можливих дій $V_{в}$ оператора та зовнішнього середовища може бути представлений за допомогою мережі Петрі $\left\langle M_{c m}, M_{\partial i и ̆}, F_{b x}, F_{\text {вux }}, m_{o}\right\rangle$, де $M_{c m}$ - множина станів середовища (позицій мережі); $M_{\partial і и ̆}-$ множина дій (переходів мережі); $F_{b x}-$ вхідна функція переходів, що визначається як $M_{c m} \times M_{\partial i и ̆} \rightarrow\{0,1\} ; F_{\text {вих }}$
- вихідна функція переходів, що визначається як $M_{\partial i \check{u}} \times M_{c m} \rightarrow\{0,1\}, m_{o}-$ вектор початкового маркування мережі.

В блоці 3.1 (рис. 1) при виконанні вправи фіксується найбільш значущі для процесу ситуації, кожна 3 яких представляє собою трійку $Y_{\text {cum. }}\left(t_{z}\right)=\left\langle S_{\text {cum. }}\left(t_{z}\right), S_{\text {cum. }}^{\prime}\left(t_{z-1}\right), V_{\text {cum. }}\right\rangle, \quad$ де $S_{\text {cum. }}\left(t_{z}\right)$ - стан моделюємого середовища в момент часу $t_{z}$, що залежить від попереднього стану

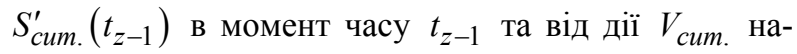
вчаємого.

В блоці 3.2 (рис. 1) здійснюється збір первинних даних про процес формування сенсомоторного навику ( $M_{\text {cum. }}$ - множина найбільш значущих ситуацій $Y_{\text {cum. }}\left(t_{z}\right) \in M_{\text {cum. }}$ з усіх зафіксованих). На підставі обробки даних обчислюються показники якості, які вимірюються в ході вправ та які формують множину $X_{я \kappa .}^{в и \kappa .} \subseteq X_{я \kappa}$, де $X_{я \kappa .}-$ множина всіх показників якості, що співставляються зі вправою на тренажері.

Показники якості характеризують результати i правильність виконання моторних дій. Приклади показників: час виконання операції; точність результату виконання; число аварійних ситуацій; точність виконання послідовності дій у порівнянні 3 розрахунковою траєкторією.

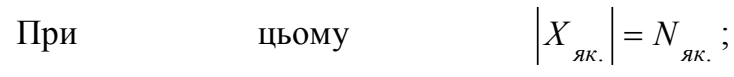
$\left|X_{я \kappa .}^{в и \kappa .}\right|=N_{я \kappa .}^{\prime}=N_{m e p .}^{\prime}+N_{\text {дин. }}^{\prime}$, де $N_{\text {mер. }}^{\prime}-$ кількість термальних показників, значення яких обчислюють-

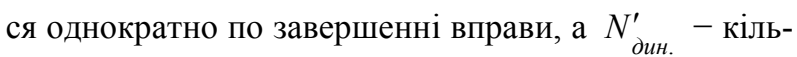
кість динамічних показників, які вимірюються багаторазово в ході проведення вправи, а також в потрібні моменти часу.

Таким чином, в блоці 3.2 (рис. 1) формуються: $P_{\text {трм. }}=\left\{P_{r}^{m p м} \mid r=\overline{\left.1, N_{\text {трм. }}^{\prime}\right\}}-\right.$ множина значень термальних показників;

$$
P_{\text {дин. }}=\left\{P_{s}^{\partial и н}\left(t_{j}\right) \mid s=\overline{1, N_{\partial и н .}^{\prime}}, j=\overline{1, N_{s}^{\partial и н} .}\right\}
$$

множина значень динамічних показників в моменти часу $t_{j}\left(N_{s}^{\partial u н .}\right.$ - кількість вимірів по $s$-му показнику).

У блоці 3.3 (рис. 1) оцінюється кожен етап формування сенсомоторного навику оператора складної системи, успішність завершення якого визначається тим, чи виконав оператор вправу задану кількість разів на необхідному рівні якості, тобто розраховується ступінь закріплення виконання операції до автоматизму.

Кожен новий етап відрізняється від поперед- 
нього додаванням нових оцінюваних показників якості. Параметри моделі (коефіцієнти оволодіння), що визначають якість виконання технологічної операції як ступінь відповідності нормативам, представляють величини на відрізку [0;1], які отримуються шляхом обробки даних про обчислені в блоці 3.2 показники якості: $M_{m p м .}=\left\{K_{r}^{m p м} \mid r=\overline{1, N_{m p м .}^{\prime}}\right\} \quad$ та $M_{\partial и н .}=\left\{K_{s}^{\partial и н}\left(t_{j}\right) \mid s=\overline{1, N_{\partial и н .}^{\prime}}, j=\overline{1, N_{s}^{\partial u н}}\right\}-$ множини коефіцієнтів оволодіння по динамічним показникам відповідно: $M_{\text {агр. }}=\left\{K_{s}^{a r p} \mid s=\overline{1, N_{\partial u н .}^{\prime}}\right\}-$ множина агрегованих коефіцієнтів оволодіння по динамічним показникам,

де

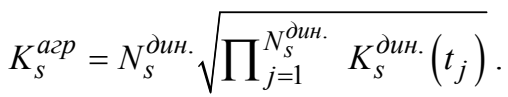

Якість виконання операції в цілому характеризується інтегральним показником - комплексним коефіцієнтом оволодіння:

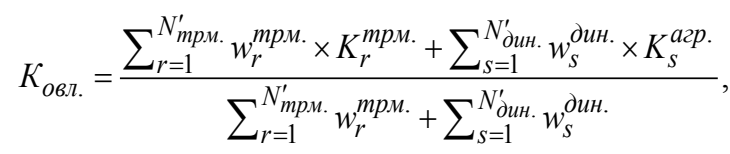

де $w_{r}^{m p м .}$ та $w_{s}^{\partial u н .}$ відповідні ваги показників якості, які можуть бути отримані, наприклад з використанням методу аналізу ієрархій.

У блоці 3.4 (рис. 1) здійснюється формування управляючих впливів (прийняття рішень) $v_{\text {ріш }}=f_{\text {рім }}\left(I_{\text {овл., }} \Delta_{\text {нав. }}\right)$ по завершенні кожного $\mathrm{i}$ перед першим виконанням вправи для визначення:

- завершеності процесу формування сенсомоторного навику в цілому або окремому етапі формування;

- підмножин рекомендуючих впливів і оцінюваних показників якості процесу при наступному виконанні вправи з урахуванням досягнутого рівня навику.

Для представлення логіко-часових особливостей генерації керувань $v_{\text {рim }}$ при багаторазовому повторенні навчаємим вправи 3 метою формування сенсомоторної навички побудована імітаційна модель у формі мережі Петрі.

Застосування мережі Петрі дозволяє формалізовано описати алгоритм прийняття рішень (представлених позиціями мережі) 3 метою організації найбільш ефективної інформаційної підтримки навчаємого у залежності від поточного рівня сформованості навички (обумовленого умовами переходів в мережі).

Траєкторії формування навичок на даному етапі для кожного навчаємого індивідуальні. Кожному оператору потрібна різна кількість повторень вправи для успішного завершення етапу. У залежності від результатів кожного 3 повторень у блоці 3.4 буде сформований відповідний керуючий вплив. У блоці 3.4 на основі накопиченої статистики про результати навчання операторів за визначений проміжок часу автоматично перераховуються значення всіх або деяких параметрів, уведених спочатку в блоці 4, iз застосуванням методів інтелектуального аналізу даних (наприклад, змінюються вид і значення параметрів кривої навчання). Може визначатися психофізіологічний стан навчаємого, (наприклад, ступінь його стомлення, напруженості роботи) по непрямих параметрах (частота переключень органів управління, частота помилок і т.д.) для прийняття рішення про продовження роботи на тренажері.

В блоці 3.5 (рис. 1) ситуація $Y_{\text {cum. }}\left(t_{z}\right)$, яка виникла в момент часу $t_{z}$ співвідноситься з розрахун-

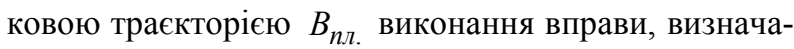
ється відхилення $\Delta_{c u m .}\left(t_{z}\right)$ від траєкторії виконання вправи (блок 2 рис. 1), тобто обчислюється значення виразу: $\Delta_{\text {cum. }}\left(t_{z}\right)=f_{\text {cum. }}^{\Delta}\left(Y_{\text {cum. }}\left(t_{z}\right), B_{\text {пл. }}\right)$.

В блоці 3.6 здійснюється генерація рекомендацій $v_{\text {рек. }}\left(t_{z}\right)$. При виконанні вправи рекомендації формуються з урахуванням залежності:

$$
v_{\text {рек. }}\left(t_{z}\right)=f_{\text {рек. }}\left(\Delta_{\text {сит. }}\left(t_{z}\right), B_{\text {пл. }}, M_{\text {рек. }}^{\prime}\right),
$$

де $M_{\text {рек. }}^{\prime}$ - множина можливих рекомендацій, $M_{\text {рек. }} \subseteq M_{\text {рек. }}^{\prime}-$ множина рекомендацій по результатам попереднього виконання вправи.

Рекомендації - це сигнали - вказівки різної модальності (тактильні, звукові, зорові, тощо) про моменти виконання оператором моторних дій, що подається на менш завантажений (в даний період часу) аналізатор. Рекомендації формуються за умови, що різниця $\Delta_{m p}$. між реальною $B_{\text {реал. та плановою }}$

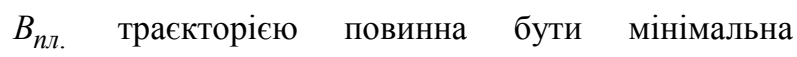
$\Delta_{m p .} \rightarrow \min$.

Алгоритми порівняння траєкторій і формування рекомендацій можуть відрізнятися для різних технологічних процесів і вправ. Подібні рекомендуючі впливи найбільш ефективні на початкових стадіях формування навичок. Чим гірше оператор виконав вправу, тим більш змістовні, деталізовані впливи повинні бути йому надані (наприклад, із фрагментами теорії, з докладним поясненням дій).

\section{Висновки}

Таким чином, в статті розроблена модель автоматизованого управління формуванням навичок у операторів складних систем. Розроблена модель управління включає побудову планованої (розрахункової) траєкторії зміни інтегрального показника 
якості виконання технологічної операції при багаторазовому повторенні вправи на основі математичного моделювання ітеративного навчання. Адекватність створеної моделі автоматизованого управління формуванням навичок операторів складних систем залежить від точності реалізації комплексу матема- тичних моделей обладнання і процесів, що дозволяє імітувати керований технологічний об'єкт у реальному масштабі часу, а також від відповідності робочого місця навчаємих, реальним робочим місцям операторів.

\section{Список літератури}

1. Новиков Д.А. Закономерности итеративного научения / Д.А. Новиков. - М.: Институт проблем управления РАН, 1998. $-77 \mathrm{c}$.

2. Остапченко Ю.Б. Персонализация процесса обучения персонала действиям в нештатных ситуациях при эксплуатации комплексов авиационной и ракетно-космической техники / Ю.Б. Остапченко // Теория и практика современной науки. - 2016. - № 2. - С. 323-330.

3. Гавриков В.Л. Континуальность типов научения: динамическое моделирование на основе теории катастроф / В.Л. Гавриков, Р.Г. Хлебопрос // Вестник Томского государственного университета. - 2010. - № 331. - С. 163-170.

4. Орлов П.А. Анализ математической модели процесса обучения / П.А. Орлов // Пожары и чрезвычайные ситуации: предотвращение, ликвидация. - 2009. - № 2. - С. 115-118.

5. Чабаненко П.П. Методология и техника разработки структурных моделей обучения операторов человекомашинных систем / П.П. Чабаненко // Збірник наукових праць Харківської української інженерно-педагогічної академії. - 2004. - № 7. - С. 73-85.

6. Чабаненко П.П. Математическое моделирование трансформационного обучения оператора человеко-машинной системы на основе структурных моделей обучения / П.П. Чабаненко, П.Н. Берлад // Системи обробки інформації. - 2010. - № 1(82). - C. 192-195.

7. Sun R. From implicit skills to explicit knowledge: A bottom-up model of skill learning / R. Sun, E. Merrill, T. Peterson // Cognitive science. - 2001. - № 2(25). - C. 203-244.

8. Комплексная визуализация предметной онтологии на основе взаимосвязанных конструкций / А.В. Ольшевская, С.К. Стафеев, К.К. Боярский, Ю.В. Катков, Д.И. Муромцев, В.И. Яговкин // Компьютерные инструменты в образовании. - 2011. - № 5. - С. 38-45.

9. Яговкин В.И. Разработка интерактивных тренажерных комплексов для освоения компетенций на основе предметных онтологий: автореф. дис. ... канд. техн. наук: 05.13.06 / Яговкин В.И. - СПб., 2012 . - 22 с.

10. Дозорцев В.М. Компьютерные тренажеры для обучения операторов технологических процессов / В.М. Дозорцев. - М.: СИНТЕГ, 2009. - 372 с.

11. Неділько В.М. Проблеми побудови системи адаптивної тренажерної підготовки диспетчерів управління повітряним рухом / В.М. Неділько, А.С. Пальоний, К.Ю. Сурков // Радіоелектронні і комп’ютерні системи. - 2017. - № 4. C. 64-72.

12. Яковенко А.Е. Стратегия принятия решений в условиях адаптивного обучения / А.Е. Яковенко, А.В. Нарожный, В.Д. Гогунский // Східно-Свропейський журнал передових технологій. - 2005. - № 2(14). - С. 105-110.

13. Верещагін I.I. Автоматизований синтез і моделі гнучких комп'ютерних професійних тренажерів широкого призначення: автореф. дис ... канд. техн. наук: 05.13.06 / Верещагін Ігор Іванович; НАН України, Міністерство освіти і науки України, Міжнародний науково-навчальний центр інформаційних технологій та систем. - К., 2007. - 20 с.

14. Борсук С.П. Адаптивне навчання операторів на функціональному тренажері: автореф. дис. канд. техн. наук: 05.07.14 / Борсук Сергій Павлович; Національний авіаційний університет. - К., 2011. - 23 с.

15. Сурков К.Ю. Метод синтезу структури системи адаптивної тренажерної підготовки диспетчерів управління повітряним рухом для підвищення ефективності навчання: дис... канд. техн. наук: 05.22.13 / Сурков Костянтин Юрійович; Льотна академія Національного авіаційного університету, Кропивницький, 2019. - 184 с.

16. Kaczor K. Overview of Expert System Shells / K. Kaczor, B. Szymon, J. Grzegorz. - Krakow: AGH University of Science and Technology, 2010.-334 c.

\section{Відомості про авторів:}

\section{Сєдаш Сергій Павлович \\ викладач}

Льотної академії національного

авіаційного університету,

Кропивницький, Україна

https://orcid.org/0000-0002-1968-8306

\section{Information about the authors:}

\author{
Serhii Siedash \\ Instructor \\ of Flight Academy \\ of the National Aviation University, \\ Kropyvnytskyy, Ukraine \\ https://orcid.org/0000-0002-1968-8306
}


Возний Олександр Олександрович старший науковий співробітник Харківського національного університету Повітряних Сил ім. І. Кожедуба, Харків, Україна https://orcid.org/0000-0002-8633-6781

\section{Oleksandr Vozny}

Senior Research Associate

of Ivan Kozhedub Kharkiv National

Air Force University,

Kharkiv, Ukraine

https://orcid.org/0000-0002-8633-6781

\title{
МОДЕЛЬ АВТОМАТИЗИРОВАННОГО УПРАВЛЕНИЯ ФОРМИРОВАНИЕМ НАВЫКОВ У ОПЕРАТОРОВ СЛОЖНЫХ СИСТЕМ
}

\author{
С.П. Седаш, А.А. Возный
}

В статье разработана модель автоматизированного управления формированием навыков у операторов сложных систем в ходе профессиональной подготовки с применением компьютерных тренажеров. Особенность модели заключается в использовании новых параметров при определении управляюших воздействий с учетом многократных повторений упражнений, что обеспечивает необходимый уровень информационной поддержки обучаемого и повымает эффективность приобретения способности к самоконтролю качества выполнения операций. Приведена структурная схема данной системы, дано описание ее составляюших. Выяснено, что оператор сложных систем должен обладать навыками своевременного, точного выполнения необходимых операций, опираясь на знания о желаемой траектории проиесса, оиенивая фактическое протекание проиесса, выбирая из возможных наиболее эффективные действия. Разработка математических моделей осуществляется с применением теории вероятностей, теории множеств, формализация процесса деятельности оператора сложных систем осуществляется с помощью теории графов и сетей Петри.

Ключевые слова: авиационные специалисты, эргатическая система, сети Петри, оператор сложной системы, сенсомоторные навыки, управление воздушным движением.

\section{A MODEL OF AUTOMATED CONTROL FOR THE FORMATION OF SKILLS IN OPERATORS OF COMPLEX SYSTEMS}

\author{
S. Siedash, O. Vozny
}

The article develops a model of automated management of skills formation among operators of complex systems in the course of professional training using computer simulators. The peculiarity of the model lies in the use of new parameters when determining control actions, taking into account multiple repetitions of exercises, which provides the necessary level of informational support for the student and increases the efficiency of acquiring the ability to self-control the quality of operations. A structural diagram of this system is given, a description of its components is given. Based on set theory and mathematical logic, the Subsystem of automated control of skill formation and description of the process of functioning of each of the units responsible for the various components of the control process, taking into account the specifics of sensorimotor skills. It was found that the operator of complex systems must have the skills of timely, accurate performance of the necessary operations, based on knowledge of the desired trajectory of the process, evaluating the actual course of the process, choosing the most effective actions from the possible ones. The development of mathematical models is carried out using the theory of probability, set theory, the formalization of the process of the operator of complex systems is carried out using the theory of graphs and Petri nets. As indicators that characterize the results and correctness of motor actions for aviation specialists are proposed: the time of the operation; accuracy of the result of execution; number of emergencies; the accuracy of the sequence of actions in comparison with the calculated trajectory. trol.

Keywords: aviation specialists, ergatic systems, Petri nets, complex system operator, sensorimotor skills, air traffic con- 